\title{
Defensive burying in the Mongolian gerbil (Meriones unguiculatus) as a function of size and shape of the test chamber
}

\author{
STEPHEN F. DAVIS, SCOTT A. MOORE, CYNTHIA L. COWEN, \\ and DEBRA K. THURSTON \\ Emporia State University, Emporia, Kansas
}

and

JOHN C. MAGGIO

Florida State University, Tallahassee, Florida

\begin{abstract}
Attempts to establish the generality of the defensive-burying response have proved quite successful with several strains of albino and hooded rats and with mice. However, three previous attempts to demonstrate this behavior in gerbils have been completely unsuccessful. Three additional defensive-burying experiments employing gerbils as subjects are reported. Defensive burying did not occur when testing took place in a rectangular chamber (Experiments 1 and 3), but did occur when a circular chamber was employed (Experiments 2 and 3). Hence, the geometric shape of the test chamber appears to be a crucial factor in determining the elicitation of this behavior in gerbils. Furthermore, the overall topography of the gerbil defensive-burying response was found to be different from that of previously examined species.
\end{abstract}

Pinel and Treit (1978) demonstrated that rats, shocked once by one of two stationary prods positioned at opposite ends of a rectangular testing chamber, selectively buried the shock prod with bedding material provided on the chamber floor. Burying was not directed toward the nonshock prod.

As a result of this original report, there has been a proliferation of research attempting to expand and delineate the parameters involved in the defensiveburying paradigm. Some of the parameters that have been investigated include: type of aversive stimulus employed (Terlecki, Pinel, \& Treit, 1979; Wilkie, MacLennan, \& Pinel, 1979), size of testing chamber (Pinel, Treit, Ladak, \& MacLennan, 1980), intensity of shock (Treit, Pinel, \& Terlecki, 1980), and type of burying material available (Pinel \& Treit, 1979).

Of particular interest to the present study is an experiment reported by Treit, Terlecki, and Pinel (1980). That investigation was concerned with the effect of organismic variables on defensive burying. It was reported that several strains of rats (i.e., Long-Evans,

This research was supported, in part, by a grant to the first author from the Research and Creativity Committee of Emporia State University. Portions of this paper were presented at the meeting of the Southwestern Psychological Association, Dallas, Texas, 1982. The mailing address for S. F. Davis, S. A. Moore, C. L. Cowen, and D. K. Thurston is: Department of Psychology, Emporia State University, Emporia, Kansas 66801. The mailing address for J. C. Maggio is: Department of Psychology, Florida State University, Tallahassee, Florida 32306.
Wistar, and Fischer) and mice (i.e., CD-1 and CF-1) engaged in burying. On the other hand, Treit, Terlecki, and Pinel (1980) reported that hamsters and gerbils did not engage in defensive burying. Similarly, Davis, Whiteside, Heck, Dickson, and Tramill (1981) reported that a variety of aversive stimuli (visual-discharge of a flashbulb; olfactory-presentation of the noxious chemical skatole; tactual-application of electric shock) failed to elicit burying in gerbils. Whillans and Shettleworth (1981) also failed to obtain burying in hamsters.

Treit, Terlecki, and Pinel (1980) suggested that the lack of burying by the hamsters and gerbils may be due to: (1) the behavior's simply not being a part of the animals' repertoire, (2) the animals' having the ability to bury, but not being able to associate the shock and the prod, or (3) the behavior's being part of the animals' repertoire, but not being elicited by the specific experimental conditions. Since neither juvenile nor adult gerbils displayed burying behavior under a variety of aversive-stimulus conditions, Davis et al. (1981) suggested that "defensive burying may well not be a behavior in the gerbil's repertoire" (p. 47). However, the effect of the specific testing situation was not evaluated by either of these experiments. ${ }^{1}$

Pinel et al. (1980) showed that, for rats, increasing the floor dimensions of the test chamber significantly reduced both the duration of burying and the height of accumulated bedding material. Because rather large testing chambers were employed in the studies that failed to observe burying in gerbils $(25 \times 45 \times 30 \mathrm{~cm}$, 
Davis et al., $1981 ; 44 \times 30 \times 44 \mathrm{~cm}$, Treit, Terlecki, \& Pinel, 1980), it is possible that this was a viable factor. If this interpretation is correct, then the use of a smaller testing chamber should result in the display of burying.

\section{EXPERIMENTS 1 AND 2}

Experiments 1 and 2 can best be viewed as pilot studies designed to determine the potential relevance of the size of the rectangular test chamber (Experiment 1) and the geometric shape of the test chamber (Experiment 2). Because the results of these two preliminary studies directly determined the design of Experiment 3 , they are described briefly.

\section{Experiment 1}

\begin{abstract}
Method
Subjects. Ten adult 60-90-day-old gerbils (five males, five females) served as subjects.

Apparatus. Testing took place in a glass and Plexiglas enclosure $(25 \mathrm{~cm}$ wide $\times 22.5 \mathrm{~cm}$ long $\times 30 \mathrm{~cm}$ high) having a $4.00-\mathrm{cm}$ floor of San-I-Cel bedding material (Paxton Processing Company, Paxton, Ill.). Two standard (metal) finishing nails extended $6.00 \mathrm{~cm}$ into the testing chamber through the center of each end (Plexiglas) wall of the chamber. The nails were mounted $1.00 \mathrm{~cm}$ above the bedding material and were separated by $1.00 \mathrm{~mm}$. One set of nails was attached to a Stoelting (Model 521C) shock source (used in all experiments) and served as a shock prod. The second set of nails served as a control prod.

Procedure. The general procedure for testing each animal began with placing it in the testing chamber for $30 \mathrm{~min}$. The first $15 \mathrm{~min}$ of this session served as a burying baseline period; that is, no aversive stimulus was presented during this time. At the end of the baseline period, each subject received a $2.50-\mathrm{mA}$ shock upon its next contact with the shock prod. Each animal then remained confined to the test chamber for a 15 -min postshock defensive-burying test session.
\end{abstract}

\section{Results}

Defensive burying, directed toward either the control or shock prod, was not displayed by any animal during either the baseline or test session. Thus, it appears that the application of a single shock is insufficient to elicit this response in the gerbil in the rectangular chamber, even when the size of the chamber is substantially reduced.

\section{Experiment 2}

Since gerbils were frequently observed digging in the corners of their rectangular housing tanks in the animal vivarium, it appears possible that the digging response competed with directed, defensive burying during test sessions. The observation that, following the application of shock in Experiment 1, the subjects tended to flee to a corner of the testing chamber supports this possibility. To evaluate this possibility, defensive-burying testing was conducted in a circular chamber in Experiment 2 .

\section{Method}

Subjects. Twenty-four 120-150-day-old Mongolian gerbils (12 males, 12 females) served as subjects.

Apparatus. A circular $(28.00 \mathrm{~cm}$ in diameter $\times 15.00 \mathrm{~cm}$ high) opaque plastic enclosure served as the testing chamber. The top of the chamber was covered with .25-in. hardware cloth, while the floor consisted of a $4.00-\mathrm{cm}$ layer of San-I-Cel. Each of two prod assemblies comprised two tenpenny nails $(8.00 \mathrm{~cm}$ long) extending through a $2.00-\mathrm{cm}$ thick block of wood. Each pair of nails was separated by a $1.00-\mathrm{mm}$ space. The two prods, one a shock prod and the other a nonshock control, were mounted directly opposite to each other on the outside of the testing chamber. When in place, the nails extended $4.30 \mathrm{~cm}$ into the chamber and $1.00 \mathrm{~cm}$ above the bedding floor. The use of a closed-circuit television allowed the test session to be conducted in complete isolation.

Procedure. Two equal groups (six males, six females), $\mathrm{S}$ (shock) and NS (nonshock), were randomly formed prior to testing. A test trial began when the designated subject had been placed in the center of the chamber, such that it was facing away from both prods, and the experimenter had left the room. A $500-\mathrm{msec}, 2.5-\mathrm{mA}$ shock was automatically delivered to each subject in Group $S$ upon its initial contact with the shock prod. Coincident with the administration of shock, a 15-min session timer was activated. The subjects in Group NS were simply confined to the chamber for $15 \mathrm{~min}$. The order in which subjects were run was determined randomly. Using a video monitor, two independent observers recorded burying times on Standard electric timers. The height of accumulated bedding material was measured at three points (left, right, and center), each point being located $1.00 \mathrm{~cm}$ from each shock prod.

\section{Results}

Because a high degree of agreement $(r=.94)$ was found between observers, the two times for each subject were averaged to yield a single, representative score. Likewise, the three height-of-accumulation scores were averaged to produce a single score for each subject. Group means reflecting time spent in defensive burying and the height of accumulated bedding material are shown in Figures 1 and 2, respectively. These figures convey a clear picture: defensive burying was displayed only by Group S. Furthermore, it is also clear that this behavior was directed only toward the prod that had delivered the shock.

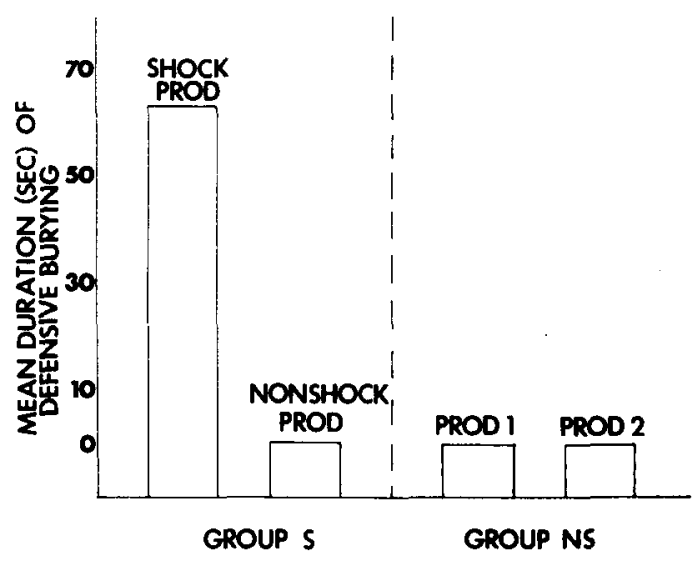

Figure 1. Mean duration (in seconds) of defensive burying directed toward the two prods by Groups $S$ and NS (Experiment 2). 


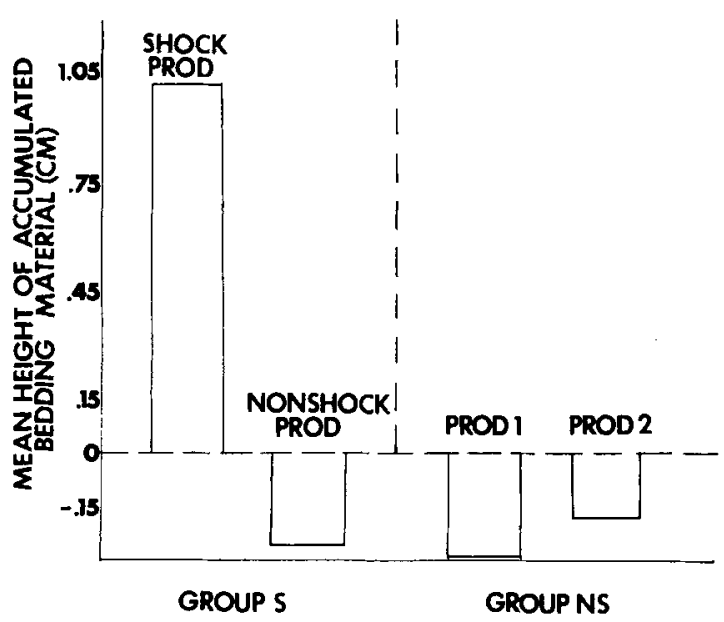

Figure 2. Mean height (in centimeters) of bedding material, relative to the initial $4.00-\mathrm{cm}$ level, accumulated around the two prods by Groups S and NS (Experiment 2).

In that directed defensive burying was completely lacking in Group NS but was exhibited by all subjects in Group S, there was complete independence of the burying score distributions. In view of this, betweengroups statistical comparisons were deemed unnecessary. A statistical comparison of the burying data of the male and female subjects constituting Group $S$ was made, however. These subjects did not differ in terms of bury. ing time $[t(10)=1.07, p>.30]$ and height of accumulated material $[\mathrm{t}(10)=.98, \mathrm{p}>.30]$.

\section{EXPERIMENT 3}

Taken collectively, the results of Experiments 1 and 2 strongly suggest that: (1) the size of a rectangular testing chamber does not appear to be related to the display of defensive burying in the gerbil, but (2) the geometric shape of the test chamber may very well be a viable parameter. These independent, preliminary results suggested the execution of a factorial experiment in which both size (small vs. large) and shape (rectangular vs. circular) of the testing chamber were simultaneously manipulated.

\section{Method}

Subjects. Eighty adult 90-day-old male gerbils served as subjects. Prior to being tested, the subjects were housed in groups of five in rectangular chambers having San-I-Cel floors. All subjects had free access to food and water in the home cages.

Apparatus. Four separate testing chambers, two rectangular and two circular, were employed. The two rectangular chambers had the following dimensions: small-25.00 $25.00 \mathrm{~cm}$ $\left(625.00-\mathrm{cm}^{2}\right.$ floor area); large- $25.00 \times 45.00 \mathrm{~cm}\left(1,125.00-\mathrm{cm}^{2}\right.$ floor area). Both rectangular chambers were $30.00 \mathrm{~cm}$ high and were constructed of glass and Plexiglas. The circular, plastic testing chambers had diameters of $28.00 \mathrm{~cm}$ (small chamber$615.77-\mathrm{cm}^{2}$ floor area) and $38.00 \mathrm{~cm}$ (large chamber-1,134.15$\mathrm{cm}^{2}$ floor area), respectively. Thus, the small chambers and large chambers were reasonably equivalent with regard to floor area. A 4.00-cm layer of San-I-Cel covered the floor of all chambers. Two sets of standard (metal) finishing nails served as shock-prod assemblies for each chamber. Both prods were mounted directly opposite to each other (on the Plexiglas end walls in the rectangular chambers), $1.00 \mathrm{~cm}$ above the bedding material covering the floor. When in place, the nails extended $4.30 \mathrm{~cm}$ into each chamber. One prod in each chamber was attached to a Stoelting (Model 521C) shock generator and served as the shock prod. To avoid the possibility of any sort of position preference, the determination of which prod was to actually deliver shock was made randomly for each subject.

Procedure. Prior to experimental testing, eight groups of equal size were formed randomly: SR-S (small rectangularshock), SR-NS (small rectangular-nonshock), LR-S (large rectangular-shock), LR-NS (large rectangular-nonshock), SC-S (small circular-shock), SC-NS (small circular-nonshock), LC-S (large circular-shock), and LC-NS (large circular-nonshock). Experimental testing was conducted in the manner described for Experiment 2, except that a $4.00-\mathrm{mA}$ shock, rather than a $2.50-\mathrm{mA}$ shock, was administered.

\section{Results}

As in Experiment 2, a high degree of observer agreement $(r=.96)$ justified the averaging of burying times for each subject. Likewise, the three height-of-accumulation scores were averaged to yield a single score for each subject.

The mean scores for duration of burying and height of accumulated bedding material are shown in Figures 3 and 4, respectively. In accord with the results of Experiments 1 and 2, only Groups SC-S and LC-S engaged in defensive burying. Furthermore, it is clear that this responding was selectively directed toward the prod that had delivered the shock.

Since burying was not observed in Groups SR-S, SR-NS, LR-S, LR-NS, SC-NS, and LC-NS, only the data from Groups SC-S and LC-S were analyzed (nondirectional $t$ tests). Corroborating the Pinel et al. (1980) findings, the results of these analyses indicated that those animals tested in the small circular chamber (Group SC-S) spent significantly more time engaged in burying $[\mathrm{t}(18)=4.22, \mathrm{p}<.001]$ and accumulated significantly more bedding material around the shock prod $[t(18)=3.74, p<.01]$ than did those animals tested in the large circular chamber (Group LC-S).

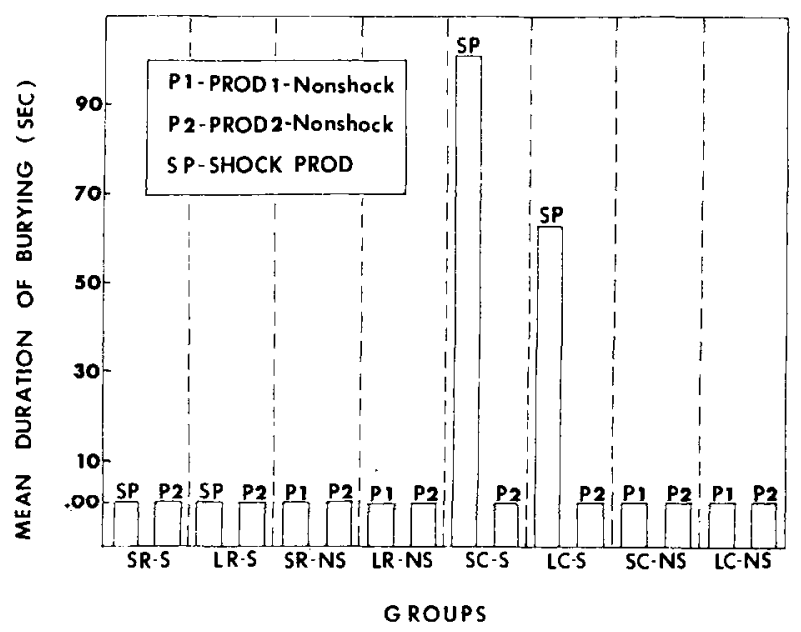

Figure 3. Mean duration (in seconds) of defensive burying directed toward the two prods by Groups SR-S, LR-S, SR-NS, LR-NS, SC-S, LC-S, SC-NS, and LC-NS (Experiment 3). 


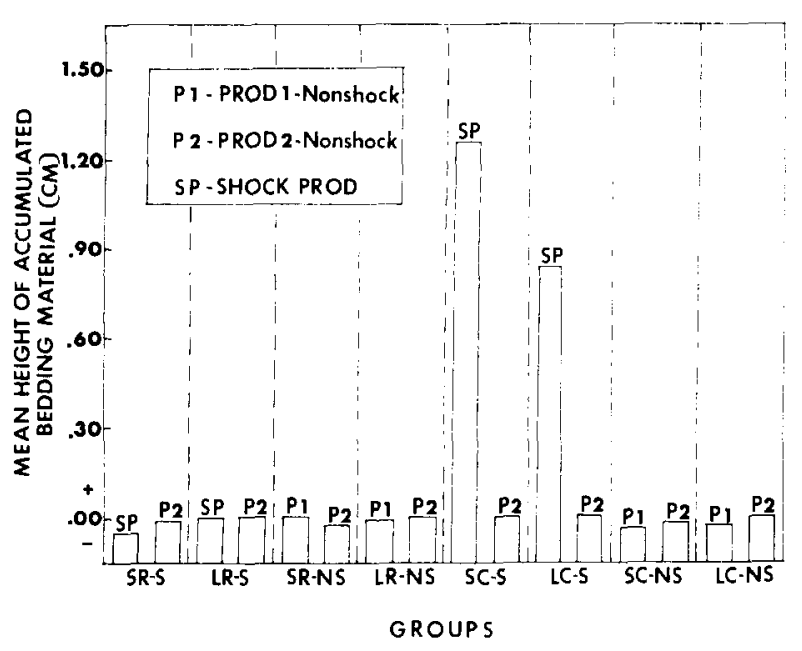

Figure 4. Mean height (in centimeters) of bedding material, relative to the initial $4.00-\mathrm{cm}$ level, accumulated around the two prods by Groups SR-S, LR-S, SR-NS, LR-NS, SC-S, LC-S, SC-NS, and LC.NS (Experiment 3).

\section{GENERAL DISCUSSION}

Demonstrating that gerbils selectively bury a prod that has delivered a single shock, while ignoring a similar, nonshock prod, extends the generality of this potentially relevant behavior to yet another rodent species. A comparison of Experiments 1 and 3 with the previous reports (Davis et al., 1981; Treit, Terlecki, \& Pinel, 1980), in which gerbil burying was not observed, prompts the following tentative conclusions. First, latent inhibition does not appear to be a contributing factor to the negative findings reported in the studies employing the rectangular test chambers. In the 15 -min baseline period of Experiment 1, the subjects made repeated nonshocked contacts with both prods prior to their receiving shock, whereas in Treit, Terlecki, and Pinel (1980) and Experiment 3, the initial contact with the shock prod resulted in the subjects' receiving shock. Burying was not observed under either condition. Second, neither the presence nor the absence of observers in the testing room appears to facilitate the display of gerbil defensive burying. Observers were present in Experiment 1 and in the Davis et al. (1981) study, but not in Experiment 3 or in Treit, Terlecki, and Pinel (1980). When testing took place in a rectangular chamber, burying was not displayed in any of these experiments. Similarly, the use of a single shock prod (Davis et al., 1981), as compared with the two-prod (shock vs. nonshock) arrangement (Treit, Terlecki, \& Pinel, 1980; Experiments 1 and 3) also does not appear to be a relevant factor. However, since the salience of employing a rectangular chamber may have overshadowed the importance of such parameters, it should be emphasized that these conclusions may pertain only to rectangularchamber testing conditions.

Since burying was shown by all animals receiving shock application in the circular chamber (Experiments 2 and 3 ), the geometric configuration of the testing chamber does appear to be highly relevant to the elicitation of this response in gerbils. Given the relevance of this parameter for gerbils, it would seem reasonable to suggest that test-chamber shape, or a similar factor, may have been responsible for Whillans and Shettleworth's (1981) negative findings in hamsters. The exact reason(s) for the importance of geometric shape are not readily apparent. Possibly, as suggested above, the corners provided by the rectangular chambers may have afforded test subjects the opportunity to engage in competing responses that interfered with the burying response. Such responses were observed in Experiments 1 and 3.

Differences between gerbil defensive burying (Experiments 2 and 3) and defensive burying typically demonstrated by rats (e.g., Davis \& Rossheim, 1980; Pinel \& Treit, 1978, 1979; Pinel et al., 1980) also merit some consideration. First, the gerbils spent less time engaged in burying and accimulated less material around the aversive stimulus than rat subjects typically have. Possibly, the relative sizes of the test animal and/or the test apparatus may account for such differences. Of potentially more interest and importance was the topography of the burying response displayed by the gerbils. Unlike the behavior pattern commonly displayed by rats and mice (i.e., the forward "snow plowing" and spraying of bedding material with the front paws), the common response of gerbils is using the hind feet to kick bedding material toward the shock prod. Along these lines, it is interesting to note that Whillans and Shettleworth (1981) reported motor-pattern differences between the rats and hamsters that they tested. They entertained the possibility that such differences may have contributed to the lack of burying in the hamsters. To our knowledge, the present findings provide the first evidence demonstrating that the defensive-burying response is not topographically constrained to forepaw utilization. Thus, employment of the defensive-burying strategy appears to transcend species differences in motor-pattern predilections. These findings also clearly establish defensive burying as part of the behavioral repertoire of the gerbil and suggest a number of fruitful avenues for future research.

\section{REFERENCES}

Davis, S. F., \& Rosshe im, S. A. Defensive burying as a function of insulin-induced hypoglycemia and type of aversive stimulation. Bulletin of the Psychonomic Society, 1980, 16, 229-231.

Davis, S. F., Whiteside, D. A., Heck, D. G., Dickson, V. A., \& Tramill, J. L. Defensive burying: A cross-species replication and extension. Bulletin of the Psychonomic Society, 1981, 17, 45-47.

Pinet, J. P. J., \& Treit, D. Burying as a defensive response in rats. Journal of Comparative and Physiological Psychology, $1978,92,708-712$.

Pinel, J. P. J., \& Theit, D. Conditioned defensive burying in rats: Availability of burying materials. Animal Learning \& Behavior, 1979, 7, 392-396.

Pinel, J. P. J., Treit, D., Ladak, F., \& Maclennan, A. J. 
Conditioned defensive burying in rats free to escape. Animal Learning \& Behavior, 1980, 8, 447-451.

Terlecki, L. J., Pinel, J. P. J., \& Treit, D. Conditioned and unconditioned defensive burying in the rat. Learning and Motivation, 1979, 10, 337-350.

Treit, D., Pinel, J. P. J., \& Terlecki, L. J. Shock intensity and conditioned defensive burying in rats. Bulletin of the Psychonomic Society, 1980, 16, 5-7.

Treit, D., Terlecki, L. J., \& Pinel, J. P. J. Conditioned defensive burying: Organismic variables. Bulletin of the Psychonomic Society, 1980, 16, 451-454.

Whillans, K. V., \& Shetrleworth, S. J. Defensive burying in rats and hamsters. Animal Learning \& Behavior, 1981, 9, 357-362.

Wilkie, D. M., Maclennan, A. J., \& Pinel, J. P. J. Rat defensive behavior: Burying noxious food. Journal of the Experimental Analysis of Behavior, 1979, 31, 299-306.

\section{NOTE}

1. However, positive pilot observations of gerbil burying made by J. Maggio and D. Harder (Department of Psychology, Florida State University) suggest that the geometric shape of the testing chamber may be a major factor in the expression of this behavior.

(Manuscript received May 26, 1982; accepted for publication June 2, 1982.) 